\title{
Desafios para a construção da 'Saúde e Ambiente" na perspectiva do seu Grupo Temático da Associação Brasileira de Saúde Coletiva
}

\author{
Challenges for the construction of 'Health and Environment \\ "in view of its Thematic Group in the Brazilian Association \\ of Collective Health
}

\author{
Lia Giraldo da Silva Augusto ${ }^{1}$ \\ Anamaria Testa Tambellini ${ }^{2}$ \\ Ary Carvalho de Miranda ${ }^{3}$ \\ Fernando Ferreira Carneiro ${ }^{4}$ \\ Hermano Castro $^{3}$ \\ Marcelo Firpo de Souza Porto ${ }^{3}$ \\ Raquel Maria Rigotto ${ }^{5}$ \\ Gabriel Eduardo Schütz ${ }^{6}$
}

${ }^{1}$ Faculdade de Ciências Médicas, Universidade de Pernambuco. R. Marq. Arnóbio 310, Santo Amaro. 50.100-130 Recife PE Brasil.lgiraldo@uol.com.br ${ }^{2}$ Comissão da Verdade, Abrasco.

${ }^{3}$ Centro de Estudos da Saúde do Trabalhador e Ecologia Humana, Escola Nacional de Saúde Pública Sérgio Arouca, Fundação Oswaldo Cruz.

${ }^{4}$ Departamento de Saúde Coletiva, Faculdade de Ciências da Saúde, Universidade de Brasília.

${ }^{5}$ Departamento de Saúde Comunitária, Universidade Federal do Ceará.

${ }^{6}$ Instituto de Estudos de Ciências da Saúde, Universidade Federal do Rio de Janeiro.

\begin{abstract}
Health and Environment' is the nucleus of knowledge and practices surrounding the relations between society and nature, mediated by the mode of production and human labor, which help to understand the determination of the health-disease process of different social classes and groups. This paper discusses the challenges to build this field from the perspective of its Thematic Group of the Association of Collective Health. The three core themes of the $2^{\text {nd }}$ Brazilian Symposium on Environmental Health are taken as the theoretical framework for analysis. A timeline of the group's trajectory, in its historical context, helps to identify the contemporary challenges. Among the main challenges identified, the challenge of building an interdisciplinary, intersectoral and participatory scientific practice, which could build knowledge and dialogue with social movements, is highlighted.
\end{abstract}

Key words Health and environment, Development, Conflicts, Social movements, Environmental justice
Resumo 'Saúde e Ambiente' é o núcleo de saberes e práticas em torno das relações entre a sociedade e a natureza, mediadas pelo modo de produção e o trabalho humano, que ajudam a compreender a determinação do processo saúde-doença das diferentes classes e grupos sociais. Este artigo discute os desafios para a construção desse campo na perspectiva do seu Grupo Temático da Associação Brasileira de Saúde Coletiva. Como marco teórico de análise adotam-se os três eixos do $2^{\circ}$ Simpósio Brasileiro de Saúde Ambiental. Para ajudar a identificar os desafios contemporâneos é traçada uma linha do tempo da trajetória do grupo no seu contexto histórico. Dentre os principais desafios identificados, destaca-se o de construir uma práxis científica interdisciplinar, intersetorial e participativa, que dialogue e construa conhecimentos com movimentos sociais.

Palavras-chave Saúde e ambiente, Desenvolvimento, Conflitos, Movimentos sociais, Justiça ambiental 


\section{Introdução}

No dinâmico processo de construção do campo da Saúde Coletiva no Brasil, desde os anos 1970, vem se constituindo também o núcleo de saberes e práticas em torno das relações entre a sociedade e a natureza, mediadas pelo modo de produção e o trabalho humano, que ajudam a compreender a determinação do processo saúde-doença das diferentes classes e grupos sociais.

Este núcleo - cujo objeto constitui-se nas interfaces entre a Saúde e o Ambiente - compartilha com o campo da Saúde Coletiva, entre outros, a característica de ser um âmbito de conhecimento científico e, ao mesmo tempo, um âmbito de práticas políticas inserido no processo histórico-social da Reforma Sanitária Brasileira (RSB). Mais que isso, reconhece a potência do diálogo entre pesquisadores, profissionais, trabalhadores, entidades civis e movimentos sociais como caminho fecundo para articular a produção de conhecimento com as transformações de sentido emancipatório, cuidando da função social da ciência e da saúde da população.

Esta rica experiência se inicia no bojo da ditadura empresarial-militar. Seus primeiros passos, ainda nos anos de 1980, foram dados junto com o denominado Novo Sindicalismo, movimento de trabalhadores articulado a partir do grito dos corpos superexplorados e adoecidos em empresas nacionais e transnacionais. No seu decorrer, foi ganhando densidade teórica e praxiológica no processo de construção da RSB.

Foi por este caminho de lutas e de debates que se construiu socialmente um novo conceito de saúde e de direito à saúde a ser garantido pelo Estado "mediante políticas econômicas e sociais". A positivação deste direito na Constituição Federal de 1988 foi uma das grandes conquistas históricas da RSB.

Tempos depois, mais precisamente no ano 2000 , no contexto de aceleração da mundialização da economia, da reestruturação socioespacial das modalidades produtivas engendrada pelos grandes grupos econômicos e, principalmente, da evidente subordinação do Estado aos interesses corporativos, constituiu-se o Grupo Temático Saúde \& Ambiente da Associação Brasileira de Saúde Coletiva (Abrasco). Ao longo dos 14 anos que se passaram, este Grupo Temático (GT) participou como promotor ou membro de várias frentes, redes e movimentos sociais, sem por isso deixar de responder à qualidade da pesquisa e do ensino nas instituições acadêmicas onde cada um de seus membros atua e tem liderança.
No seu momento atual, o GT assumiu o de-

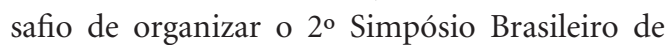
Saúde e Ambiente (II SIBSA) ${ }^{1}$, a ser realizado em outubro de 2014 em Belo Horizonte, MG. O evento está sendo convocado sob o título Desenvolvimento, Conflitos Territoriais e Saúde: Ciência e Movimentos Sociais para a Justiça Ambiental nas Políticas Públicas, e será abordado em três eixos: (i) Desenvolvimento Socioeconômico e conflitos territoriais; (ii) A função social da ciência, ecologia de saberes, e outras experiências de produção compartilhada de conhecimento; (iii) Direitos, justiça ambiental e políticas públicas. O evento coloca sua estrutura sustentada em um tripé, tanto para o debate como para a proposição de ação: 1) leitura crítica do contexto; 2) compreensão dos conceitos e 3) a orientação da prática das políticas públicas de saúde e outras afins para enfrentar os problemas de saúde da população.

Em outras palavras, o II SIBSA está sendo organizado sob inspiração do aprendizado adquirido com conquistas e frustrações vivenciadas no percurso dos 14 anos de atuação do GT. Um percurso pautado nos desafios de contribuir, desde uma perspectiva científica, na construção de caminhos alternativos ao modelo de desenvolvimento proposto, que sejam promotores de justiça, de equidade, de dignidade e de vida em todas as suas expressões.

Neste sentido, este artigo se propõe discutir os desafios para a construção de um núcleo de conhecimentos e práticas na interface entre a Saúde e o Ambiente, inserido no campo da Saúde Coletiva, a partir da perspectiva do Grupo Temático da Abrasco como uma de suas instâncias estruturantes. Primeiro, proporemos uma discussão teórico conceitual de cada um dos três eixos propostos no II SIBSA, uma vez que eles constituem o marco analítico dos desafios identificados na perspectiva do GT Saúde \&Ambiente da Abrasco. Posteriormente, traçaremos uma linha do tempo associando e discutindo a trajetória do GT com os desafios contemporâneos de um tempo histórico caracterizado por profundas mudanças nos modos de produção social e de vida no seu sentido mais amplo.

\section{Os eixos do II SIBSA}

\section{Desenvolvimento Socioeconômico e Conflitos Territoriais}

A qualidade e a integridade dos ecossistemas constituem condições indispensáveis para pro- 
duzir e reproduzir formas singulares de vida, organizadas em comunidades tão diversas quanto os processos históricos que as determinam e as possibilitam existir material e simbolicamente. Diversidade e singularidades que, desde os primórdios da Modernidade, têm se mostrado antagônicas aos processos de acumulação do capital, vulgarmente denominados 'desenvolvimento econômico'. Decerto, a capacidade destruidora de diversidades (ecológicas e culturais) do chamado 'avanço civilizatório pelo progresso científico e tecnológico' - ao menos na concepção colonialista da burguesia eurocêntrica - já era evidente no início da primeira revolução industrial na Inglaterra. A essência desta contradição foi relatada no século XIX, nos clássicos ensaios de Engels ${ }^{2}$ sobre a degradada situação da classe trabalhadora; e de Marx ${ }^{3}$, sobre a origem do capital como resultado de um processo de acumulação primitiva, a começar pela apropriação privada de terras comunais e a consequente expulsão dos povos que durante séculos as habitavam.

A perversa mistura de processos de degradação, apropriação e expulsão é um padrão inerente e iniludível ao modo capitalista de produção, tanto quanto é a exploração do trabalhador assalariado. As contradições do capitalismo referem-se à degradação/destruição de alguns ecossistemas (zonas de sacrifício) combinada com a oposição das classes sociais em relação à apropriação do usufruto dos benefícios produzidos pelo modelo produtivo (inequidade). $\mathrm{O}$ fundamento deste antagonismo subjaze no fato de que somente é possível que uns poucos privilegiados acumulem riqueza ao custo que outros muitos - que contribuem para produzi-la - sejam violentamente expropriados do controle sobre as condições de produção (força de trabalho; recursos territoriais; subjetividades e poder simbólico).

Os processos de expropriação e/ou exclusão não se realizam sem que se manifeste algum tipo de conflitividade/resistência por parte dos coletivos atingidos. A magnitude e a modalidade de um conflito social dependerão da conjuntura em que se realizam os processos históricos de apropriação dos recursos territoriais.

No atual cenário nacional, o Estado brasileiro tem favorecido a consolidação de um modelo de desenvolvimento econômico que facilita o avanço irrestrito do Capital sobre os ecossistemas, mercantilizando bens e serviços que sustentam as comunidades locais de vida. Neste contexto, a acumulação por espoliação territorial, além de gerar conflitos sociais, incide fortemente na determinação do processo saúde-doença individual e coletivo com graves implicações sobre a vida, o adoecimento e a morte, sendo que os efeitos mais adversos deste modelo atingem especialmente grupos sociais vulnerabilizados.

Abordar esta temática, que se expressa no local, mas que possui força de determinação global, constitui um desafio à ciência e às práticas acadêmicas, bem como às políticas públicas e aos próprios grupos sociais que se organizam em defesa de seus direitos, articulando diversas estratégias de resistência.

\section{A função social da ciência, ecologia de saberes, e outras experiências de produção compartilhada de conhecimento}

O modelo hegemônico de ciência, fortemente influenciado pelas ciências naturais, tem por base a separação entre corpo e espírito, homem e natureza e entre sujeito e objeto. A racionalidade cartesiana desse modelo e sua pretensa superioridade em relação a outras formas de saber se justificariam por sua objetividade e neutralidade. Nessa visão, a realidade 'objetiva' seria alcançada através da descoberta de relações estáveis (leis) obtidas a partir de fragmentos de realidade, que configuram os objetos das ciências disciplinares.

Tal forma de produção de conhecimento e sua aplicação prática no campo das tecnologias possui forte funcionalidade com a lógica da produção industrial e do progresso econômico, com uma visão restrita, individualista e consumista da vida e da natureza que favorece sua mercantilização.

Este modelo de ciência hegemônica favorece a abordagem descontextualizada e despolitizada da realidade, que desconsidera dimensões éticas, incertezas e outras formas de produzir saberes. Autores como Boaventura de Sousa Santos afirmam que a ciência moderna, especializada e disciplinar, vem promovendo uma espécie de "epistemicídio", ou seja, uma exclusão, marginalização e silenciamento dos demais saberes".

Deve levar-se em consideração que o contexto de geração de nocividades ambientais e à saúde humana configura-se em dois grandes eixos ontogênicos: o modelo de desenvolvimento econômico-social e a produção de conhecimento, ambos interligados e subordinados a lógica da acumulação capitalista.

A ciência moderna, nascida nas sociedades ocidentais e datada na emergência histórica da Burguesia, vem cumprindo o papel imprescindível de subsidiar o desenvolvimento da civilização do Capital. Se muitos benefícios são frutos do sistema técnico-científico, também é verdade que a 
tecnologia não é externa às relações sociais e de poder e que muitos dos perigos que enfrentamos na atualidade provêm das próprias intervenções feitas por meio deste mesmo sistema técnicocientífico ${ }^{5}$.

Ao romper com a falsa neutralidade científica, assumimos o desafio de contribuir para a construção de uma ciência que vá ao mundo vivo recolher seus objetos de estudo, a partir das lentes da sensibilidade engajada, ao encontro daqueles que sofrem, dos grupos humanos e das classes sociais mais vulneráveis ${ }^{6}$, embora isto possa significar até a criminalização dos pesquisadores engajados com as lutas sociais dos vulnerabilizados, dos oprimidos e dos humilhados.

É fundamental o desenvolvimento de um posicionamento crítico em saúde e ambiente fundado na construção de alternativas de produção compartilhada de conhecimentos e sua relação com a práxis. Teremos desafios, ameaças e alternativas para realizar uma ciência engajada ou militante nas universidades e centros de pesquisas. O primeiro desafio neste sentido é criar, reconhecer e valorizar novos métodos de pesquisa coerentes com essa ciência crítica e engajada. Para isto, é fundamental transformar o discurso crítico em relação à Ciência Moderna em experiências de pesquisas que impliquem em participação dos sujeitos vulnerabilizados em todas as etapas da geração de conhecimento para transformar os territórios pesquisados, e conformar novas redes e teias de colaboração.

\section{As questões da territorialidade e das desigualdades sociais}

Com a ampliação da globalização do capital, estão ocorrendo processos de reconfiguração da ordem econômica, marcados pelos movimentos históricos de dominação e subordinação. Há uma intensificação na hierarquização social, aprofundando a concentração dos meios de produção e a divisão social do trabalho. $\mathrm{O}$ estabelecimento diferencial de centros de produção, de distribuição e de consumo vem afetando a organização social e espacial das cidades, em suas funções de reprodução social.

Não se observa apenas um desigual ritmo de crescimento das cidades articulado à modernização forçada do campo, mas uma profunda desigualdade de distribuição de recursos, que possibilita a existência de áreas e de populações vulnerabilizadas. De modo geral, esses dois condicionantes se agregam a outros da determinação social da saúde.
Vemos também uma reprodução do domínio econômico e simbólico dos meios de circulação e comunicação nos territórios de desenvolvimento social, afetando as comunidades que ficam mais expostas a situações de risco, tais como: a falta de políticas de educação, de saúde, de infraestrutura urbana, de habitação, de reforma agrária, de segurança e soberania nutricional, de proteção ambiental; a violência no campo e nas cidades; a contaminação ambiental, os processos migratórios induzidos pelos grandes empreendimentos e a violação de direitos.

É por esta razão que os temas de direitos humanos e de justiça ambiental são fundamentais para se analisar as políticas públicas. O conceito de justiça ambiental é importante por integrar a dimensão ambiental com as do direito e da democracia através de ações transformadoras ${ }^{7}$.

A noção de território tem sido objeto de estudos, especialmente pela Geografia Crítica, com Josué de Castro e de Milton Santos, que nos brindaram com profundas reflexões sobre o modo de produção do espaço social ${ }^{8}$. Esse debate inaugural se ampliou com os processos de globalização do capital e do trabalho?.

Como sabemos, o Estado sempre ocupou um papel preponderante na produção do espaço social mediante políticas públicas, conferindo-lhes uma natureza ideológica e política, realizando a expansão das cidades, sustentando a competição e a reprodução ampliada do capital. O Estado vai produzir o território como espaço político, isto é, de luta política decorrente dos conflitos e contradições que se instauram pela acumulação capitalista. De fato, na prática, as políticas públicas são pensadas sem a noção de território ou de espaço social, e acabam por produzir indicadores que ocultam as vulnerabilidades e os vulnerabilizados; e as ações desencadeadas tendem a ser perdulárias, ineficazes e muitas vezes perigosas ${ }^{10}$.

O conhecimento das particularidades das experiências sociais, que inclui as relações de produção, as formas de reprodução, de circulação, de consumo, a cultura e o exercício do poder nos acontecimentos que afetam a vida das pessoas é o caminho que possibilita aos sujeitos sociais e às comunidades um protagonismo para a condução dos processos de promoção e proteção da saúde e da vida ${ }^{11}$.

O conhecimento do campo simbólico nas práticas coletivas pode orientar as possibilidades de mudança e de produção do novo ${ }^{12}$. E que não se estabelece de fora, mas que requer sujeitos implicados e não guiados por razões instrumentais beneficiárias da acumulação capitalista. 
As macropolíticas ditadas pelo Agronegócio e pelo Plano de Aceleração do Crescimento têm impactado negativamente os territórios e os espaços sociais, ampliando as desigualdades sociais e as injustiças ambientais. Estas, não reveladas por indicadores de interesse mercadológico, mas pelos relatos das comunidades onde se instauram a degradação ambiental, as violências e as violações de direitos.

Este modelo de crescimento econômico ocorre em meio a um processo de desregulação do Estado, quando mais ele seria necessário, pela grave crise do Sistema Único de Saúde, pela baixa capacidade escolar e baixa qualificação profissional, pelo avanço das fronteiras agrícolas sobre áreas indígenas e de proteção ambiental, pela agudização da violência no campo e nas cidades, pela intensificação dos conflitos de terra, todos a requerer políticas públicas adequadas.

As iniciativas no campo da Saúde Pública para as vigilâncias dessas problemáticas são cada vez menos expressivas do ponto de vista do cuidado da saúde. Nos territórios onde pessoas e comunidades são afetadas por grandes empreendimentos, as ações da saúde são limitadas, na sua maioria, pelo caráter assistencialista, reduzido à medicalização e ao clientelismo político. As questões de territorialidade, de desregulamentação do estado, da flexibilização do código sanitário lato sensu e da violência no campo e na cidade estão entre alguns dos desafios que requerem a internalização do conceito de ambiente como bem comum e difuso nas práticas da Saúde Coletiva.

\section{O GT de Saúde e Ambiente da Abrasco e os desafios do tempo histórico}

As questões que a partir de aqui propomos discutir sobre o tema "saúde e ambiente" devem ser lidas e refletidas na singularidade da conjuntura de nossa época; no contexto do atual desenvolvimento econômico-social brasileiro inserido nos processos de globalização. Neste sentido, encontramos o desafio, parafraseando Mészáros ${ }^{13}$, de pensar o tempo histórico em tempos que demandam interpretações globais.

A linha do tempo do Grupo Temático (GT) de Saúde \& Ambiente da Abrasco se inicia em 2000, na conjuntura da construção de uma 'Política Nacional de Saúde Ambiental' (PNSA) no âmbito do Sistema Único de Saúde SUS. O GT não se furtou do desafio de aportar suas contribuições ao esforço coletivo demandado pela construção de políticas públicas, apoiando as iniciativas do Ministério da Saúde neste sentido. Todavia, até o momento não foi alcançada uma definição formal para a PNSA. Seria este um dos reflexos da subordinação das políticas sociais aos imperativos do Programa de Aceleração do Crescimento (PAC)? Seria inconveniente para o Estado brasileiro, neste momento, explicitar qual é a política pública que efetivamente está em vigência, e que se manifesta em suas omissões e descaminhos?

Neste mesmo contexto, o GT encarou o desafio de produzir um intenso trabalho de reflexão teórica e de colaboração direta com as ações da chamada 'Vigilância em Saúde Ambiental' no âmbito dos programas de pós-graduação de Saúde Pública/Saúde Coletiva. Mais especificamente, o desafio consistiu em buscar modos de atender a demanda de capacitação técnica para a Rede de Saúde Estadual e Municipal. Estas ações fomentaram diversas vigilâncias especializadas como da Água, do Solo, do Ar, dos Desastres (naturais e tecnológicos) e das Substâncias perigosas. No entanto, essas 'vigilâncias' foram sendo implementadas pelo órgão competente seguindo o modo operante da Saúde Pública desde o século XIX, ou seja, considerando o ambiente como uma externalidade, e concentrando-se exclusivamente em um modelo causal linear sobre a produção de nocividades para a saúde humana ${ }^{14}$. Assim, apesar do esforço acadêmico de propor um modelo diferente, com base em uma abordagem eco-sócio-sanitária que dê conta da complexa diversidade dos processos que determinam a saúde e a vida da população, não se alcançou uma organização integrada no território. Permaneceu a fragmentação das 'vigilâncias' e, consequentemente, a reprodução de ações de baixa eficácia, pouco integradas à Atenção Primária à Saúde e a outros setores relevantes, como a Saúde do Trabalhador ${ }^{15}$.

Em 2007, logo após o lançamento do PAC pelo governo Lula, foi realizado em Brasília, em setembro de 2007, o "Seminário sobre Saúde Ambiental e Saúde do Trabalhador e suas interfaces com o Programa de Aceleração do Crescimento" 16 promovido pelo GT Saúde \& Ambiente da Abrasco; áreas de Saúde Ambiental e Saúde do Trabalhador da Secretaria de Vigilância à Saúde do Ministério da Saúde (DVSAST/SVS/MS); e do Conselho Nacional de Saúde (CNS), por meio da Comissão Intersetorial de Saneamento e Meio Ambiente (Cisama) junto com o Conselho Nacional de Saúde. Este seminário expressou a compreensão da indissociabilidade do modelo de desenvolvimento vigente no país - que privilegia a produção de commodities agrícolas e minerais - com processos produtivos que geram enormes 
impactos socioambientais. Os participantes do evento assumiram o desafio da elaboração de medidas que preservassem a saúde das populações atingidas por esses empreendimentos, desde a elaboração dos projetos às suas execuções. Para frustração dos envolvidos, esta possibilidade foi excluída da agenda federal e os efeitos deletérios desta política têm sido reiteradas vezes revelados.

Ciente da missão de aprofundar o processo de aproximação da academia com os movimentos sociais, o GT organizou o $1^{\circ}$. Simpósio Brasileiro de Saúde e Ambiente (SIBSA), realizado em Belém (PA) em 2011, sob o tema "Ciência e Saúde Ambiental - Teorias, Metodologias e Práxis". O inventário "Quem é quem na saúde ambiental brasileira"17, pesquisa apoiada pelo DVSAST/SVS/MS e pela Fundação Oswaldo Cruz (Fiocruz), contribuiu na preparação deste evento, uma vez que identificar os sujeitos acadêmicos e da sociedade civil relacionados com a interface entre a Saúde e o Ambiente foi importante para constatar sua magnitude e abrangência nacional. Resta agora o desafio de aprofundar este mapeamento, por meio de uma pesquisa com levantamento de dados primários, identificando os objetos de pesquisa, os referenciais teóricos, os recursos instrumentais e metodológicos e a forma em que os resultados são participados socialmente.

Também em 2011, o GT teve uma importante oportunidade de aproximação com movimentos sociais; de aprendizado sobre suas metodologias de construção de conhecimento; de articulação política; e de aprofundamento da análise sobre as relações entre o modelo de desenvolvimento e a saúde da população ao participar do Encontro Diálogos e Convergências entre Agroecologia, Saúde e Justiça Ambiental, Soberania Alimentar, Economia Solidária e Feminismo, promovido pelas grandes redes nacionais voltadas a estes temas. Internamente à Abrasco, oportunizou o diálogo e a participação conjunta de seus Grupos Temáticos, possibilitando pontes interdisciplinares e incitando novas formas de articulação na associação.

Esta vivência contribuiu fortemente na decisão e na metodologia de construção do Dossiê Abrasco: um alerta sobre os impactos dos agrotóxicos na saúde ${ }^{18}$, em conjunto com os GT de Saúde do Trabalhador; Nutrição; Vigilância Sanitária; e Promoção da Saúde.

Neste contexto, o GT Saúde \& Ambiente decidiu fortalecer a 'Campanha Permanente contra os Agrotóxicos e pela Vida', uma iniciativa lançada por amplo conjunto de movimentos sociais rurais e seus aliados, trazendo a público as evi- dências científicas dos graves danos dos agrotóxicos e deste modelo de desenvolvimento à saúde da população. Organizado em três partes, cada uma delas lançou o debate em grandes eventos como o World Nutrition Congress; a Cúpula dos Povos na Rio + 20; e o X Congresso Brasileiro de Saúde Coletiva, todos em 2012 19 .

O 'Dossiê Abrasco' colocou esse debate a partir do lugar de uma ciência não subordinada na agenda nacional e latino-americana. Analisou o contexto global e nacional em que se realizam as políticas sustentadoras "revolução verde", evidenciando sua funcionalidade à sustentação dos interesses do agronegócio ao custo da degradação socioambiental. Ainda mostrou a significativa potência para a produção de conhecimentos em processo de diálogos e convergências de saberes, um caminho que reinstala o desejo que esteve presente na XVIII Conferência Nacional de Saúde em 1986, marcando uma firme posição pela redemocratização do país e pela garantia da saúde como um direito humano.

Nesta linha do tempo, não poderia faltar a menção da realização de três encontros de programas de Pós-graduação em Saúde Pública/ Coletiva que contam com linhas de pesquisa em 'Saúde \& Ambiente' ou em "Saúde Ambiental”. Os dois primeiros - em 2010 e 2011 - realizados por iniciativa do Instituto de Estudos em Saúde Coletiva da Universidade Federal do Rio de Janeiro (IESC/UFRJ); e o terceiro articulado pela Coordenação da Pós-Graduação e pelo Núcleo Tramas da Universidade Federal do Ceará (2013) e realizado pelo GT de Saúde e Ambiente da Abrasco. Nestes encontros participaram pesquisadores e docentes de Programas de Pós-Graduação que desenvolvem áreas de concentração, linhas de pesquisa ou atividades identificadas no núcleo da Saúde \& Ambiente no campo da Saúde Coletiva. Estes encontros foram momentos singulares para debater os desafios da construção deste núcleo no meio acadêmico, posto que está atravessado por um processo de produtivismo e avaliacionismo, que nada mais é do que a incidência da lógica capitalista associada ao cientificismo positivista da produção intelectual. Em efeito, muitas produções intelectuais desenvolvidas no campo acadêmico exigem o mesmo rigor metodológico de uma pesquisa, mas não recebem valoração significante pelos sistemas de avaliação acadêmica, tais como o Dossiê Abrasco sobre Saúde e Agrotóxicos; as Notas Técnicas de Reavaliação de Registros de Agrotóxicos; a comunicação de resultados de pesquisas para os sujeitos da investigação, no formato de cartilhas para 
educação popular; e os pareceres técnicos para o Ministério Público. Elaborações deste tipo, embora cientificamente rigorosas, são consideradas produções técnicas sem valor pelo sistema avaliativo dos programas de Pós-graduação no Brasil, que apenas privilegiam o formato paper e as publicações em revistas indexadas de alto impacto nacional e internacional ${ }^{7}$.

Contudo, mesmo com essa adversidade, a perspectiva de atuação acadêmica do núcleo de Saúde \& Ambiente está consolidando-se. Neste sentido, o GT está pautado na independência de pensamento, com abertura à sociedade e criatividade em sua produção científica. O acúmulo teórico decorrente de seus Diálogos Interdisciplinares - uma série de sessões com convidados das diferentes correntes do pensamento para debates produzidas pelo GT entre 2000 e 2010 - e pela reflexão crítica permanente tem conferido ao referido GT a produção de experiências acadêmicas claramente pautadas pelos problemas do mundo real. Isto lhe permitiu editar um caderno com teses para apoiar o debate da I Conferência Nacional de Saúde Ambiental além de números temáticos em revistas indexadas tais como a Revista Brasileira de Epidemiologia e a Revista Ciência \& Saúde Coletiva, ambas da Abrasco; e os Cadernos de Saúde Coletiva do IESC/UFRJ.

Finalmente, cabe destacar que no GT foi gestada a criação da Comissão da Verdade da Reforma Sanitária ${ }^{21}$, assumida como agenda da Abrasco. Toda luta ambientalista, sanitária, ecológica é necessariamente uma luta pela memória histórica, pela vida, pela paz e contra a guerra, contra qualquer violação dos direitos humanos nos seus aspectos econômicos, sociais, culturais, ambientais, ou melhor, no desrespeito à dignidade humana.

\section{Conclusões}

No percurso de atuação do GT há uma derivação provocada, por um lado, negativamente, pela frustração de ainda não ter sido alcançada uma definição formal da PNSA para a qual a I Conferência Nacional de Saúde Ambiental, realizada em 2010, teria trazido os subsídios; bem pela frustração de não ter podido incidir na agenda do PAC no sentido de proteger à saúde da população dos impactos socioambientais acarretados pelo projeto.

Por outro lado, positivamente, está o posicionamento intelectual crítico dos membros do GT, apoiado pela direção da Abrasco, pela adoção de abordagens sistêmicas e de pesquisa-ação, bem como pelo engajamento progressivo junto aos movimentos sociais que reivindicam justiça ambiental, direitos humanos, saneamento ambiental, agroecologia, segurança e soberania nutricional, dentre outros.

Discutir sobre o tema "saúde e ambiente", na perspectiva da função social da ciência e da construção compartilhada de conhecimentos em tempos que demandam interpretações globais não é tarefa fácil. Pelo contrário, trata-se de um grande desafio, pois estamos acostumados a atuar em sistemas cognitivos fechados pela disciplinaridade, em linhas de pesquisa desconexas da realidade; ou por conta de políticas governamentais guiadas pelo pragmatismo eleitoral e clientelista.

A prática e a reflexão teórica no núcleo "Saúde \& Ambiente" no campo da Saúde Coletiva exige cada vez mais uma perspectiva interdisciplinar, intersetorial e de inclusão social pela via da participação política e do efetivo diálogo com os saberes dos sujeitos que vivem nos territórios onde se desenrolam os processos implicados na determinação da saúde e da vida. Essa complexidade não se limita às 'caixinhas' disciplinares, tais como a da epidemiologia, da toxicologia, da análise de políticas, das ciências humanas e sociais, dentre outras configuradas nos espaços acadêmicos tradicionais, mas as integra e, ainda, demanda articulações inovadoras como a Ecologia Política e a Justiça Ambiental.

Reconhecemos também a necessidade de se pensar e consolidar uma ética da saúde pública, pensada na perspectiva da ética da proteção ${ }^{22}$, que necessariamente internalize o tratamento de questões ambientais que derivam em processos de vulnerabilização de coletivos sociais, em especial, aqueles relacionados à inequidade na distribuição dos benefícios e dos "malefícios" do crescimento econômico.

A proposição de uma forma de produzir conhecimento científico na saúde coletiva, enlaçando saúde e ambiente, com a intenção de se tornar uma proposição 'emancipadora', tem possibilitado desdobramentos nessa nova etapa da caminhada do GT de Saúde \& Ambiente da Abrasco, por meio de suas iniciativas coletivas e por iniciativa de alguns de seus membros.

Os resultados, até agora, demonstraram que uma forma particular de articulações teóricometodológicas e de pesquisadores- comunidades/sujeitos da investigação (agentes do processo do trabalho da pesquisa) geraram profícuas discussões entorno a uma práxis que seja coerente com os propósitos declarados de mobilizar esses saberes em favor da saúde coletiva. 
Seria, portanto, necessário estruturar um 'Fórum' interdisciplinar e intersetorial que amalgame essas e outras questões fundantes de um campo que expresse o pensamento e o modo de fazer próprios da Saúde Coletiva para os problemas de 'Saúde \& Ambiente'. Contudo, há hoje, no âmbito da Abrasco, condições acolher este debate? Qual estratégia seria necessária implementar nesse sentido?

Outro desafio, que afeta principalmente as condições necessárias para consolidar o núcleo Saúde \& Ambiente nos programas de Pós-graduação em Saúde Coletiva, está constituído pela lógica produtivista e avaliacionista dos sistemas de avaliação e qualificação das produções científicas de seus docentes e pesquisadores. Este problema é gerador de um profundo mal-estar no interior dos programas de pós-graduação, que também estão guiados pelo pragmatismo das avaliações de progresso e pelo gerencialismo do setor privado imposto à universidade pública. Um efeito de engessamento do poder criativo dos grupos de pesquisa que inibe ou desestimula, dentre outras capacidades, as atividades de pesquisa com o movimento social. Embora o núcleo Saúde \& Ambiente da Saúde Coletiva esteja colhendo diversos frutos do intenso trabalho desenvolvido nos últimos anos; deve também enfrentar a reação de alguns poucos cientistas, acostumados a utilizar a indústria da dúvida para favorecer o status quo dos interesses do grande capital ${ }^{23,24}$.

Resta ainda, mencionar o desafio do engajamento social dos pesquisadores, uma postura ética que, em certas ocasiões, representa o custo de ver-se envolvido em processos judiciais como, de fato, já tem acontecido com vários pesquisa- dores brasileiros criminalizados por denunciar a associação entre atividades produtivas específicas e impactos ambientais e a saúde humana. Dessa forma, é urgente pautar a necessidade de garantir a autonomia da atividade acadêmica em relação às pressões ou aos interesses econômicos.

Mesmo com esses desafios, a produção científica dessa área de conhecimento vem se tornando expressiva, ganhando um espaço de 'subárea' da Saúde Coletiva denominada de "Saúde e Ambiente”, pelo CNPq, a partir de 2013.

Este reconhecimento representa um grande passo adiante na consolidação do núcleo Saúde \& Ambiente da Saúde Coletiva, mas ainda é insuficiente, pois muitas questões continuam em aberto, a saber: Quais são seus principais significantes e significados para o entendimento do processo saúde-doença? Que abordagens são requeridas para responder às demandas da sociedade, especialmente das comunidades locais atingidas pelos processos globalizados de acumulação capitalista?

Hoje nos pautamos pelo desafiante apoio à construção de caminhos alternativos ao modelo de desenvolvimento socioeconômico atualmente vigente no Brasil, caracterizado pela injusta distribuição social e territorial dos ônus e dos bônus do crescimento da economia. Neste sentido, criticamos a proposta de 'desenvolvimento sustentável' hoje apropriada pelo capitalismo trasvestido na bandeira da "economia verde" 25 . Acreditamos que não faz mais sentido insistir na utilização de um termo que foi ressignificado pelo Capital para adequá-lo aos seus interesses, muito frequentemente, contrários à saúde em seu conceito mais amplo, aos ecossistemas e à diversidade cultural, ou melhor, contrários à vida em seu sentido mais amplo.

\section{Colaboradores}

LGS Augusto, AT Tambellini, AC Miranda, FF Carneiro, H Castro, MFS Porto, RM Rigotto e GE Schütz participaram igualmente de todas as etapas de elaboração do artigo. 


\section{Referências}

1. Associação Brasileira de Saúde Coletiva (Abrasco). $2^{\circ}$ Simpósio Brasileiro de Saúde e Ambiente. s/d. [página na internet]. [acessado 2014 maio 30]. Disponível em: http://www.sibsa.com.br/

2. Engels F. A situação da classe trabalhadora na Inglaterra. São Paulo: Global Editora; 1985.

3. Marx K. A origem do Capital: A acumulação primitiva. 6a ed. São Paulo: Global Editora; 1989.

4. Santos BS, Meneses MP. Epistemologias do Sul. São Paulo: Cortez; 2010.

5. Haesbaert R, Porto-Gonçalves CW. A nova des-ordem mundial. São Paulo: UNESP; 2006.

6. Rigotto RM, organizador. Agrotóxicos, trabalho e saúde: vulnerabilidade e resistência no contexto da modernização agrícola no Baixo Jaguaribe/CE. Fortaleza: Edições UFC; 2011.

7. Firpo MPS. Complexidade, processos de vulnerabilização e justiça ambiental: um ensaio de epistemologia política. Rev. Crítica de Ciências Sociais 2011; 93:31-58

8. Santos M. Por uma Geografia Nova. São Paulo: Hucitec, Edusp; 1978.

9. Santos M. Território, globalização e fragmentação. São Paulo: Hucitec; 1994.

10. Rigotto RM, Augusto LGS. Saúde e ambiente no Brasil: desenvolvimento, território e iniqüidade social. Cad Saude Publica 2007; 23(Supl. 4):S475-S501.

11. Torres H. Segregação residencial e políticas públicas: São Paulo na década de 1990. Rev. Brasileira de Ciências Sociais 2004; 19(54):41-56.

12. Cassab MAT, Ribeiro LC, Schettino, P. Desigualdade social e território: uma breve reflexão. II Jornada Internacional de Políticas Públicas. Maranhão, 23-26 de agosto de 2005 [página na internet]. [acessado em 2014 maio 30] Disponível em: http://www.joinpp.ufma.br/ jornadas/joinppIII/html/Trabalhos2/Maria_Aparecida _Luiz_Claudio_Priscila297.pdf

13. Mészáros I. O Desafio e o fardo do tempo histórico. São Paulo: Boitempo; 2007

14. Câmara MV, Tambellini AT. Considerações sobre o uso da epidemiologia nos estudos em saúde ambiental. Rev. Bras. Epidemiol. 2003; 6(2):95-104.

15. Abuquerque KM, Augusto LGS. O Programa de Saúde Ambiental da Cidade do Recife-uma experiência bem sucedida e seus desafios. In: Augusto LGS, Carneiro RM, Martins PH, organizadores. Abordagem Ecossistêmca em Saúde - Ensaios para o controle de dengue. Recife: Universitária UFPE; 2005. p. 263-278.

16. Seminário PAC. Documento Sintese Ampliado. 27 de setembro de 2007 [página na internet] [acessado em 2014 maio 30]. Disponível em: www.saudecomunitaria.ufc. br/PAC\%20Saude.pdf

17. Freitas CM, Tambellini AT, Schütz GE, Bertolini VA, Franco Netto FA. Quem é quem na saúde ambiental brasileira? Identificação e caracterização de grupos de pesquisas e organizações da sociedade civil. Cien Saude Colet 2009; 14(6):2071-2082.

18. Carneiro FF, Pignati W, Rigotto RM, Augusto LGS, Rizollo A, Muller NM, Alexandre VP, Friedrich K, Mello MSC. Dossiê ABRASCO - Um alerta sobre os impactos dos agrotóxicos na saúde. Parte 1. Rio de Janeiro, abril de 2012. [página na internet]. [acessado em 2014 maio 30]. Disponível em: http://www.abrasco.org.br/UserFiles/File/ABRASCODIVULGA/2012/DossieAGT.pdf
19. Augusto LGS, Carneiro FF, Pignati W, Rigotto RM, Friedrich K, Faria NMX, Burigo AC, Freitas VMT, Guiducci Filho E. Dossiê ABRASCO - Um alerta sobre os impactos dos agrotóxicos na saúde. Parte 2. Rio de Janeiro, junho de 2012 [página na internet]. [acessado em 2014 maio 30]. Disponível em: http://www.abrasco. org.br/UserFiles/Image/DOSSIE2f.pdf.

20. Rigotto RM, Porto MF, Folgado C, Faria NM, Augusto LGS; Bedor C. Burigo A, Carneiro FF, Castro FP, Fernandes GB; Ferreira MJM, Friedrich K, Marinho AMCP, Monteiro D, Pignatti W, Pinheiro TMM, Rizzolo A, Silva N, Tygel A. Dossiê ABRASCO - Um alerta sobre os impactos dos Agrotóxicos na Saúde. Parte 3 - Agrotóxicos, conhecimento científico e popular: construindo a Ecologia de Saberes. Porto Alegre, novembro de 2012. [página na internet]. [acessado em 2014 maio 30]. Disponível em: http://www.contraosagrotoxicos. org/index.php/materiais/relatorios/dossie-abrasco-um -alerta-sobre-os-impactos-dos-agrotoxicos-na-saude -parte-3/download

21. Associação Brasileira de Saúde Coletiva (Abrasco). Comissão da Verdade da Reforma Sanitária. s/d. [página na internet] [acessado em 2014 mai 30]. Disponível em: http://cvrs.icict.fiocruz.br/

22. Schramm FR, Kottow M. Principios bioéticos en salud pública: limitaciones y propuestas. Cad Saude Publica 2001; 17(4):949-956.

23. Mali T. Fruto Proibido. Revista Galileu no 266 setembro de 2013. [página na internet] [acessado em 2014 maio 30] Disponível em: http://conseaminas.blogspot.com. br/2013/09/revista-galileu-divulga-polemica-sobre. html.

24. Fundação Oswaldo Cruz (FIOCRUZ), Associação Brasileira de Saúde Coletiva (ABRASCO) e Instituto Nacional do Câncer (INCA) alertam para o risco do uso de agrotóxicos. Nota conjunta 10 de setembro de 2013. [material da internet]. [acessado em 2014 maio 30]. Disponível em https://portal.fiocruz.br/pt-br/content/ em-nota-conjunta-fiocruz-inca-e-abrasco-alertam -para-o-risco-do-uso-de-agrot $\% \mathrm{C} 3 \% \mathrm{~B} 3 x \mathrm{xicos}$.

25. Schütz GE, Tambellini AT, Asmus CIRF, Meyer A, Câmara VM. A agenda da sustentabilidade global e sua pauta oficial: uma análise crítica na perspectiva da Saúde Coletiva. Cien Saude Colet 2012; 17(6):1407-1418.

Artigo apresentado em 07/07/2014

Aprovado em 09/07/2014

Versão final apresentada em 10/07/2014 